\title{
I want to be a paediatric cardiologist: is it too late?
}

Peter J Lillitos (1)

Department of Congenital Cardiology, Leeds General Infirmary, Leeds Teaching Hospitals NHS Trust, Great George St, Leeds LS1 3EX, UK

It is Spring 2020, and I am 7 months into my transformation from general paediatrician to paediatric cardiologist. I am in my late 30s. I have travelled the well trodden path of 6 years in medical school, over a decade in paediatric training, and then a year as a consultant paediatrician. I have now gone back into speciality training to become a paediatric cardiologist.

Why after investing so much time and energy to reach the top of the mountain, go back and do it all again? The essence of my answer is: I realised late, I climbed the wrong mountain.

In brief, I had accredited myself as a paediatrician with expertise in cardiology. My one year experience in cardiology was immensely enjoyable and I toyed with the idea of switching into cardiology training. However, I decided to stay on track. I had just 2 years of general paediatric training left and with some cardiology skills I figured I would be onto a good thing for future paediatrician jobs. Two years flew past and I was appointed to a consultant paediatrician post with a cardiology interest. The initial excitement of being a "boss" soon wore off when I realised that my special interest was the only part of the job I really enjoyed. The retraining niggle grew into an intolerable itch. Twelve months into the job I came to the realisation that I was never going to be happy in this role.

Now the pipe dream of retraining became a serious thought. I had 3 decades left until I reach state pension age. Would an extra $4-5$ years as a trainee be so bad versus years of feeling regretful? On the other hand, why throw away financial and geographical security. I spoke at length with my wife, a great rock of support. She is a school teacher and a great listener. She fully got the pros and cons of what such a career reboot would mean for me personally and the family. Her overriding advice was to pursue happiness. My happiness, and by the same token unhappiness, transmits to the home. It was her who one evening, waved an article on our coffee table in front of my nose and said, "Read this, it's about you!"”

Being a trainee again did not bother me so much. It was not that long ago I was in that role. The clinical and coping skills I had acquired through my career would ground me well. Professionally, I felt I had a lot to lose if I my application was unsuccessful. I confided in a handful of close colleagues whose message was surprisingly supportive. "Careers are long and are not sustainable if you are unhappy. Don't have regrets."

I took the plunge. I applied for a number. I took a philosophical view with regard to failure. Whatever the outcome, at least I would know that I had tried and that "what if" would have been addressed.

Anyway, to move the story on, I was successful. I have a new mountain to climb but I am enjoying every minute. I have since met a handful of colleagues in my new speciality who also took the long way round in their careers, for the same reason I am, and have never looked back.

Reflecting on the above: I am not saying one speciality is superior to the other. I am not advocating my path should be the norm nor would I even recommend it if avoidable. It is incredibly more convenient to make these decisions earlier. However, life does not always work that way for everyone. For me, I came to realise my passion later in my career. I am also incredibly lucky. Several planets aligned including family support, my age, health, and financial circumstances. The reason I want to share my story is to demonstrate that careers are not necessarily set in stone and it is okay to change one's mind.

Conflicts of interests. None.

\section{Reference}

1. Rimmer A. Should I change specialty? I'm not happy. BMJ 2018; 363: k4304. doi: 10.1136/bmj.k4304 [published Online First: 2018/10/14]. 